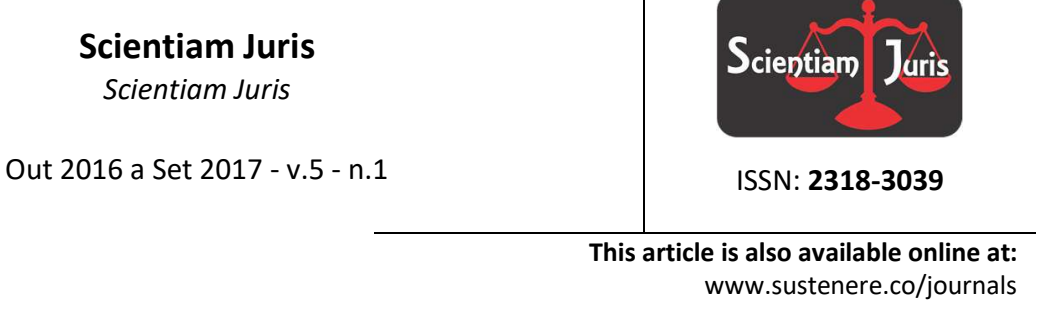

\title{
A importância do Mercosul para o Brasil
}

A importância de um bloco como o Mercosul acaba sendo estratégica. Ainda que os países da América do Sul tenham as suas fragilidades, não ter um bloco seria ainda mais fatal. A existência do bloco também faz com que tais países possam, dentro das suas limitações, dialogar com outros blocos mais fortes. O Mercosul é o grande expoente brasileiro no cenário internacional, nas relações econômicas e até mesmo políticas, possibilitando uma maior estrutura de negociação ao gozar do status de bloco econômico.

Palavras-chave: Mercosul; Importância; Brasil.

\section{The importance of Mercosur to Brazil}

The importance of a bloc like Mercosur ends up being strategic. Although the countries of South America have their weaknesses, not having a block would be even more fatal. The existence of the bloc also allows such countries to, within their limitations, dialogue with other stronger blocs. Mercosur is the great Brazilian exponent in the international scene, in economic and even political relations, allowing a greater structure of negotiation by enjoying the status of economic bloc.

Keywords: Mercosur; Importance; Brazil.

Topic: Direito Internacional

Reviewed anonymously in the process of blind peer.
Received: 09/06/2017

Approved: 17/08/2017 


\section{INTRODUÇÃO}

Este processo de integração tem início após a Segunda Guerra Mundial, quando os países começaram a verificar a importância da integração econômica para sua abertura comercial. O Mercado Comum do Sul (Mercosul) é um amplo projeto de integração concebido inicialmente por Argentina, Brasil, Paraguai e Uruguai. No aspecto econômico, o Mercado assume hoje o caráter de União Aduaneira, mas seu fim último é se constituir em um verdadeiro Mercado Comum, seguindo os objetivos estabelecidos no Tratado de Assunção, por meio do qual o bloco foi fundado, em 1991. A formação do bloco implica na livre circulação de bens, serviços e fatores produtivos entre os países, através da eliminação dos direitos alfandegários e restrições não-tarifárias à circulação de mercadorias e de qualquer outra medida de efeito equivalente.

Em sua formação original, o bloco era composto por Argentina, Brasil, Paraguai e Uruguai; mais tarde, ele aderiu à Venezuela, que no momento se encontra suspensa. O bloco se encontra em fase de expansão, uma vez que a Bolívia aguarda a ratificação parlamentar de seu protocolo de adesão como membro pleno, documento que necessita, para sua vigência, das aprovações legislativas na Bolívia, no Brasil e no Paraguai, pois os demais parlamentos já o aprovaram.

As origens do Mercosul estão ligadas às discussões para a constituição de um mercado econômico regional para a América Latina, que remontam o tratado que estabeleceu a Associação Latino-Americana de Livre Comércio (ALALC) desde a década de 1960. Esse organismo foi sucedido pela Associação LatinoAmericana de Integração (ALADI) na década de 1980. À época, a Argentina e o Brasil fizeram progressos na matéria, assinando a Declaração do Iguaçu (1985), que estabelecia uma comissão bilateral, à qual se seguiram uma série de acordos comerciais no ano seguinte. O Tratado de Integração, Cooperação e Desenvolvimento, assinado entre ambos os países em 1988, fixou como meta o estabelecimento de um mercado comum, ao qual outros países latino-americanos poderiam se unir. Aderiram o Paraguai e o Uruguai ao processo, e os quatro países se tornaram signatários do Tratado de Assunção (1991), que estabeleceu o Mercado Comum do Sul, uma aliança comercial visando dinamizar a economia regional, movimentando entre si mercadorias, pessoas, força de trabalho e capitais.

Inicialmente foi estabelecida uma zona de livre comércio, na qual os países signatários não tributariam ou restringiriam as importações um do outro. A partir de $1^{\circ}$ de janeiro de 1995 , essa zona converteu-se em união aduaneira, na qual todos os signatários poderiam cobrar as mesmas quotas nas importações dos demais países (tarifa externa comum). No ano seguinte, a Bolívia e o Chile adquiriram o estatuto de associados. Outras nações latino-americanas manifestaram interesse em entrar para o grupo. Em 2004, entrou em vigor o Protocolo de Olivos (2002), que criou o Tribunal Arbitral Permanente de Revisão do Mercosul, com sede na cidade de Assunção (Paraguai), por conta da insegurança jurídica no bloco sem a existência de um tribunal permanente. Dentre acordos econômicos firmados entre o Mercosul e outros entes, estão os Tratados de Livre Comércio (TLC) com Israel, assinado no dia 17 de dezembro de 2007, e com o Egito, assinado em 02 de agosto de 2010. 
Em 23 de maio de 2008, foi assinado o Tratado Constitutivo da União de Nações Sul-Americanas (UNASUL), composta pelos doze estados da América do Sul e fundada dentro dos ideais de integração sulamericana multissetorial. A organização conjuga as duas uniões aduaneiras regionais: o Mercosul e a Comunidade Andina (CAN). O cargo de Secretário-Geral da UNASUL fornece à entidade uma liderança política definida no cenário internacional, sendo um primeiro passo para a criação de um órgão burocrático permanente para uma união supranacional, que eventualmente substituirá os órgãos políticos do Mercosul e da CAN.

\section{DISCUSSÃO TEÓRICA}

O Mercosul é considerado uma "união aduaneira imperfeita". Isso porque não existe uma zona de livre circulação de mercadorias plena entre os seus membros. Ainda que tenha havido reduções significativas das tarifas comerciais em muitos setores, muitos produtos uruguaios, paraguaios, argentinos e venezuelanos não estão livres de barreiras para ingressar no Brasil - e vice-versa. Da mesma forma, há uma extensa lista de exceções para a aplicação da Tarifa Externa Comum nas negociações com outros países. Essa "união aduaneira imperfeita" ocorre porque as economias dos países-membros são bastante assimétricas - o PIB do Brasil, por exemplo, é 75 vezes maior que o do Paraguai. Dessa forma, o Mercosul acaba estabelecendo algumas brechas, com mecanismos para não prejudicar as economias menos dinâmicas e os setores econômicos mais sensíveis à concorrência externa.

Outra crítica feita ao Mercosul diz respeito ao fato de que as normas do bloco dificultam o estabelecimento de acordos de livre-comércio com outros países e blocos econômicos. Atualmente, o Mercosul possui acordos desse tipo somente com Egito, Israel e Palestina. As negociações com a União Europeia, iniciadas há mais de uma década, estão travadas porque não há consenso entre os membros do bloco. Como um acordo deve ser feito conjuntamente, e os interesses dos membros do Mercosul são divergentes em muitos aspectos, o impasse permanece. Além disso, os países que fazem parte do bloco não podem negociar acordos comerciais individualmente. Por exemplo, as normas da Tarifa Externa Comum restringem a possibilidade de o Brasil fechar um acordo de livre-comércio com o Japão se o Uruguai não quiser. Ou se negocia em bloco ou nada feito.

Como se não bastassem todas as dificuldades de integração econômica, o Mercosul encontra-se rachado politicamente. O Uruguai exerceu a presidência rotativa de seis meses à frente do bloco até o final de julho, mas um impasse político impediu a transferência do poder. O próximo país na fila para assumir o posto seria a Venezuela, seguindo a ordem alfabética, conforme determina o regimento do bloco.

No entanto, Argentina, Brasil e Paraguai não aceitam que a Venezuela assuma a presidência do Mercosul. Estas nações alegam que os venezuelanos tiveram 4 anos, desde o ingresso do bloco em 2012, para cumprir todas as regras de adesão ao bloco, e não o fizeram. Isso impediria a Venezuela não só de assumir a presidência do Mercosul como poderia levar o país a ser rebaixado no bloco, deixando de ser membro pleno. Já o Uruguai não vê nenhum impedimento jurídico para transferir o comando à Venezuela. 
Mas há outras questões econômicas e políticas que impedem a posse da Venezuela como presidente do Mercosul. O país atravessa uma grave crise de abastecimento e vive um momento de efervescência política, com o fortalecimento da oposição contra o governo do presidente Nicolás Maduro. Argentina, Brasil e Paraguai também criticam o comprometimento da Venezuela com os direitos humanos e a democracia, e acusam o país de manter presos políticos, o que fere as normas do Mercosul.

A oposição à Venezuela dentro do Mercosul também é reflexo da mudança de ventos políticos na região. A Venezuela é o principal expoente da esquerda bolivariana, que se caracteriza pela adoção de políticas nacionalistas e a oposição ao neoliberalismo e aos Estados Unidos. O país ingressou no Mercosul em 2012, tendo como principais fiadores os governos de centro-esquerda do Brasil, da Argentina e do Uruguai. O único país contrário à Venezuela era o Paraguai, governado pela centro-direita. Mas à época da aprovação do ingresso da Venezuela no Mercosul, o Paraguai estava suspenso do bloco em virtude do impeachment do presidente Fernando Lugo, que foi efetuado em um procedimento considerado antidemocrático pelos países-membros.

Todavia, a balança ideológica mudou na América do Sul. No final de 2015, a Argentina elegeu como presidente o empresário de centro-direita Mauricio Macri e o Brasil consumou o impeachment de Dilma Rousseff, que foi substituída por Michel Temer, de perfil liberal-conservador. Esses fatores são considerados cruciais para entender por que a Venezuela perdeu o apoio de Brasil e Argentina neste momento de definição da presidência do Mercosul. O Uruguai, que continua governado pela centro-esquerda, é o único paísmembro a apoiar a posse da Venezuela como presidente do bloco.

Brasil, Argentina, Paraguai e Uruguai, fundadores do Mercosul, decidiram em 05 de agosto de 2017, de forma unânime, suspender a Venezuela por "ruptura da ordem democrática". É a segunda vez que o bloco aplica essa decisão contra um país-membro desde a sua criação. Essa é a segunda vez que o Mercosul, fundado em 1991, aplica essa cláusula assinada em 1998 em Ushuaia, na Argentina, ratificada e ampliada em 2011. Ela estipula que "a plena vigência de instituições democráticas é essencial" para a integração regional.

Na prática, essa decisão muda em pouco, ou nada, a situação do país no grupo, já que a Venezuela se encontra suspensa do Mercosul desde dezembro por descumprir obrigações comerciais com as quais se comprometeu ao se incorporar ao bloco em 2012.

\section{A importância do MERCOSUL para o Brasil}

Três pilares sustentam o Mercosul: o econômico, o social e o da cidadania. No aspecto econômico, o Mercosul é um bloco de união aduaneira. Nesse âmbito, ele tem como objetivo criar um mercado comum entre seus Estados-Partes. No pilar social, o Mercosul busca promover a articulação de políticas públicas regionais, relacionadas a temas como fome e erradicação da pobreza, universalização da educação e da saúde pública, e valorização e promoção da diversidade cultural, entre outros. Já na dimensão da cidadania, o bloco trabalha para implantar políticas que permitam a livre circulação de pessoas e a promoção dos direitos civis, sociais, culturais e econômicos, assim como a garantia da igualdade de condições e acesso ao trabalho, educação e saúde. 
O Mercosul tem PIB nominal de US\$3,2 trilhões, o que significa que se ele fosse considerado como um único país, ocuparia a quinta economia do mundo. De acordo com informações do próprio Mercosul, o comércio dentro do bloco multiplicou-se mais de 12 vezes em 20 anos. Ele saltou de US\$4,5 bilhões em 1991, para US\$59,4 bilhões em 2013. Das exportações brasileiras para o Mercosul, 87\% é composta de produtos industrializados.

O bloco como um todo é uma potência no ramo agrícola, principalmente na produção de trigo, milho, soja, açúcar e arroz. O Mercosul é o maior exportador líquido mundial de açúcar, o maior produtor exportador mundial de soja, o 1 ㅇ produtor e o 2 o maior exportador mundial de carne bovina, o 4ㅇ produtor mundial de vinho, o 9o produtor mundial de arroz, e um grande produtor e importador de trigo e milho.

O bloco é, também, uma grande potência energética. Ele detém 19,6\% das reservas provadas de petróleo do mundo. Possui 3,1\% das reservas de gás natural e 16\% das reservas de gás recuperáveis de xisto. A maior reserva de petróleo do mundo é do Mercosul, com mais de 310 bilhões de barris em reservas certificadas pela OPEP. Desse montante, a Venezuela, que têm 92,7\% das reservas de petróleo do Mercosul, concorre com uma reserva de 296 milhões de barris.

Em 2011, a corrente total de comércio do Brasil com o Mercosul atingiu o recorde histórico de US\$47,228 bilhões, sendo US\$27,852 bilhões de exportações e US\$19,375 bilhões em importações. O volume recorde da corrente comercial em 2011 é 05 vezes superior ao registrado em 2002, US\$8,930 bilhões, mostrando que, apesar das críticas, o Mercosul se tornou um enorme sucesso comercial nos últimos 10 anos.

O Mercosul já responde pelo maior superávit comercial do Brasil, com um movimento financeiro que superou a marca de US\$2 bilhões, sendo o principal mercado para as exportações brasileiras de manufaturados. De acordo com o Ministério das Relações Exteriores, um quarto dos produtos vendidos para o exterior tem o Mercosul como destino. O saldo "geral" da balança comercial brasileira foi positivo no primeiro semestre de 2015. De janeiro a junho o Brasil exportou US\$94,3 bilhões e importou US\$92,1 bilhões.

Dados do Ministério do Desenvolvimento, Indústria e Comércio indicam que em 2014, o Brasil exportou US\$20,4 bilhões para os países que formam o bloco. Os produtos industrializados, em especial os manufaturados, respondem por US\$17,1 bilhões deste valor. Desde o primeiro ano de existência (1991), o objetivo de ampliar as relações comerciais entre os seus componentes foi alcançado. Na ocasião, as exportações brasileiras para os demais países do Mercosul encerraram o ano com alta de 75\% na comparação com 1990, totalizando US\$2,3 bilhões. O Mercosul é, além disso, o maior mercado para as sete mil micro, pequenas e médias empresas exportadoras brasileiras, visto que $20 \%$ das exportações dessas empresas são destinadas para os membros do bloco.

Um dos pontos de destaque dentro do histórico do Mercosul é a integração da cadeia produtiva de automóveis entre Brasil e Argentina. Em conjunto, os dois são o terceiro maior mercado de automóveis no mundo, perdendo apenas de China e Estados Unidos. Em 2013, 47\% da produção de automóveis argentinos foram exportados para o Brasil. Na outra mão, $80 \%$ dos carros que o Brasil vendeu para o exterior foram para o país vizinho. 
Os números da balança comercial refletem a importância do Mercosul como bloco econômico. O grupo contabiliza um crescimento de mais de 12 vezes nas transações comerciais entre seus membros: de US\$4,5 bilhões no ano de sua criação para US\$59,4 bilhões em 2013.

Em tempos de tantas crises econômicas, pensar na importância de um bloco como o Mercosul acaba sendo estratégico. Ainda que os países da América do Sul e o próprio México tenham as suas fragilidades, não ter um bloco seria ainda mais fatal. A existência do bloco também faz com que tais países possam, dentro das suas limitações, dialogar com outros blocos mais potentes. É como se estivéssemos em um grande mar. Todos podem tentar recolher peixes, mas é claro que há formas mais robustas de traze-los à rede. Entretanto, em meio à tempestade, um pequeno barco pode ser útil às grandes embarcações, e vice-versa.

\section{Organização e estrutura do Mercosul}

O Mercosul estrutura-se a partir de alguns organismos representados pelos países-membros efetivos do bloco que visam à correta estruturação dos acordos realizados. Esse bloco econômico possui três grupos diferentes de países integrantes:

Membros permanentes: são aqueles países que fazem parte integralmente do Mercosul, adotam a TEC e compõem todos os acordos do bloco, além de possuírem poderes de votação em instâncias decisórias. São membros permanentes a Argentina, o Brasil, o Paraguai e o Uruguai. (A Venezuela foi aceita como membro permanente em 2012 e suspensa do bloco em dezembro de 2016 e em 05 de agosto de 2017);

Membros associados: são aqueles países que não fazem parte totalmente dos acordos do Mercosul, principalmente por não adotarem a TEC, mas que integram o bloco no sentido de ampliar suas trocas comerciais com os demais países do bloco. São membros associados a Bolívia, o Chile, a Colômbia, o Equador, o Peru, o Suriname e a Guiana; e

Membros observadores: composto pelo México e pela Nova Zelândia, esse grupo é destinado aos países que desejam acompanhar o andamento e expansão do bloco sem o compromisso de dele fazer parte, podendo tornar-se um membro efetivo ou associado no futuro. No caso do México, isso será muito difícil, haja vista que esse país já compõe outros dois blocos: o NAFTA e a APEC.

Em termos de organização interna e estruturação, o Mercosul é formado por algumas instituições que detêm funções específicas e buscam assegurar o bom andamento e o desenvolvimento do bloco, são elas:

a) CMC (Conselho do Mercado Comum): É o principal órgão do Mercosul, sendo responsável pelas principais tomadas de decisões no bloco. É composto pelos Ministros das Relações Exteriores e da Economia de todos os membros efetivos e apresenta duas reuniões por ano, sendo a presença dos presidentes obrigatória em pelo menos uma dessas reuniões;

b) GMC (Grupo Mercado Comum): É o órgão executivo do Mercosul, sendo composto por representantes titulares e alternativos de cada um dos membros efetivos do bloco. Esse grupo reúne-se trimestralmente, mas pode haver encontros extraordinários a pedido de qualquer um dos seus partícipes;

c) CCM (Comissão de Comércio do Mercosul): É o órgão responsável pela gestão das decisões sobre o comércio do Mercosul. Suas funções envolvem a aplicação dos instrumentos políticos e comerciais dentro do bloco e deste com terceiros, além de criar e supervisionar órgãos e comitês para funções específicas;

d) CPC (Comissão Parlamentar Conjunta): representa os parlamentos dos países-membros do Mercosul. É o órgão responsável pela operacionalização e máxima eficiência do corpo legislativo do bloco; e 
e) Foro Consultivo Econômico e Social: é o órgão que representa os setores da economia e da sociedade de cada um dos membros do Mercosul. Ele possui um caráter apenas consultivo, opera por meio de recomendações ao GMC e pode incluir em torno de si a participação de empresas privadas.

Além desses organismos, existem outros órgãos e secretarias vinculados às denominações acima apresentadas. Juntos, esses elementos compõem a estrutura do Mercosul, atuando no sentido de organizálo e fundamentar suas ações e estratégias de mercado. O seu correto funcionamento significa a garantia da coesão e harmonia desse importante bloco econômico.

\section{Protocolos complementares ao tratado fundador}

Em razão da dinâmica presente no processo de integração, para adequar a estrutura do bloco às mudanças ocorridas, o Conselho do Mercado Comum anexou ao Tratado de Assunção diversos protocolos complementares ao longo do tempo. Para ter validade, após receber a assinatura dos presidentes do bloco, um protocolo geral deve ser aprovado por decreto legislativo em todos os países signatários. Ao todo, 15 protocolos receberam esta aprovação e estão em vigência:

Protocolo de Las Leñas, 1992: determinou que sentenças provenientes de um país signatário tenham o mesmo entendimento judicial em outro, sem a necessidade de homologação de sentença a que estão submetidas todas as demais decisões judiciais tomadas em países de fora do bloco. No Brasil, esse protocolo foi aprovado através do decreto legislativo número 55 de 19 de abril de 1995 e promulgado por meio do decreto número 2.067, de 12 de novembro de 1996;

Protocolo de Buenos Aires sobre Jurisdição Internacional em Matéria Contratual, 1994: no Brasil, esse protocolo foi aprovado pelo decreto legislativo número 129, de 05 de outubro de 1995, e promulgado através do decreto número 2.095, de 17 de dezembro de 1996;

Protocolo de Integração Educativa e Reconhecimento de Certificados, Títulos e Estudos de Nível Primário, Médio e Técnico, 1994: no Brasil, esse protocolo foi aprovado através do decreto legislativo número 101, de 3 de julho de 1995, e promulgado por meio do decreto número 2.726, de 10 de agosto de 1998;

Protocolo de Ouro Preto, 1994: estabeleceu estrutura institucional para o Mercosul, ampliando a participação dos parlamentos nacionais e da sociedade civil. Esse foi o protocolo que deu ao Mercosul personalidade jurídica de direito internacional, tornando possível sua relação com outros países, organismos internacionais e blocos econômicos. No Brasil, este protocolo foi aprovado através do decreto legislativo número 188, de 16 de dezembro de 1995, e promulgado por meio do decreto número 1.901, de 09 de maio de 1996;

Protocolo de Medidas Cautelares, 1994: no Brasil, esse protocolo foi aprovado através do decreto legislativo número 192, de 15 de dezembro de 1995 e promulgado por meio do decreto número 2.626, de 15 de junho de 1998;

Protocolo de Assistência Jurídica Mútua em Assuntos Penais, 1996: no Brasil, esse protocolo foi aprovado através do decreto legislativo número 03, de 26 de janeiro de 2000, e promulgado por meio do decreto número 3.468 , de 17 de maio de 2000;

Protocolo de São Luís em Matéria de Responsabilidade Civil Emergente de Acidentes de Trânsito entre os Estados Partes do Mercosul, 1996: no Brasil, esse protocolo foi aprovado através do decreto legislativo número 259 , de 15 de dezembro de 2000 , e promulgado por meio do decreto número 3.856, de 3 de julho de 2001;

Protocolo de Integração Educativa para a Formação de Recursos Humanos a Nível de PósGraduação entre os Países Membros do Mercosul, 1996: no Brasil, esse protocolo foi 
aprovado pelo decreto legislativo número 129 , de 05 de outubro de 1995, e promulgado através do decreto número 2.095, de 17 de dezembro de 1996;

Protocolo de Integração Cultural do Mercosul, 1996: no Brasil, esse protocolo foi registrado através do decreto legislativo número 03, de 14 de janeiro de 1999, e promulgado através do decreto número 3.193, de 05 de outubro de 1999;

Protocolo de Integração Educacional para o Prosseguimento de Estudos de PósGraduação nas Universidades dos Países Membros do Mercosul, 1996: No Brasil, esse protocolo foi aprovado através do decreto legislativo número 2, de 14 de janeiro de 1999, e promulgado por meio do decreto número 3.194, de 5 de outubro de 1999;

Protocolo de Ushuaia, 1998: no Brasil, esse protocolo foi aprovado através do decreto legislativo número 452, de 14 de novembro de 2001 e promulgado através de decreto número 4.210, de 24 de abril de 2002;

Protocolo de Olivos, 2002: aprimorou o Protocolo de Brasília mediante a criação do Tribunal Arbitral Permanente de Revisão do Mercosul. Esse tribunal passou a revisar laudos expedidos pelos Tribunais Arbitrais, em caso de contestação. Seus árbitros são nomeados por um período de dois anos, com possibilidade de prorrogação. As decisões deste tribunal têm caráter obrigatório para os Estados envolvidos nas controvérsias, não estão sujeitas a recursos ou revisões e, em relação aos países envolvidos, exercem força de juízo. No Brasil, esse protocolo foi registrado através do decreto legislativo número 712, de 15 de outubro de 2003, e promulgado por meio do decreto número 4.982, de 9 de fevereiro de 2004;

Protocolo de Assunção sobre o Compromisso com a Promoção e Proteção dos direitos Humanos no Mercosul, 2005: no Brasil, este protocolo foi registrado através do decreto legislativo número 592, de 27 de agosto de 2009 e promulgado por meio do decreto número 7.225, de 1 de julho de 2010;

Protocolo Constitutivo do Parlamento do Mercosul, 2005: no Brasil, esse protocolo foi aprovado através do decreto legislativo número 408, de 12 de setembro de 2006 e promulgado por meio do decreto número 6.105, de 30 de abril de 2007; e

Protocolo de Adesão da República Bolivariana de Venezuela ao Mercosul, 2006: Protocolo válido em razão da suspensão da República do Paraguai. No Brasil, esse protocolo foi registrado através do decreto legislativo número 936, de 16 de dezembro de 2009 e promulgado por meio do decreto número 3.859, de 6 de dezembro de 2012 .

Alguns protocolos não receberam esta aprovação e, por esse motivo, são chamados de protocolos pendentes. Sem embargo, outros protocolos aprovados por decreto legislativo foram aprimorados posteriormente, tendo assim, sua validade revogada:

Protocolo de Brasília, 1991: foi revogado com a assinatura do Protocolo de Olivos, em 2002. Modificou o mecanismo de controvérsias inicialmente previsto no Tratado de Assunção, disponibilizando a utilização de meios jurídicos para a solução de eventuais disputas comerciais. Estipulou a utilização do recurso de arbitragem como forma de assegurar ao comércio regional estabilidade e solidez. Definiu prazos, condições de requerer o assessoramento de especialistas, nomeação de árbitros, conteúdo dos laudos arbitrais, notificações, custeio das despesas, entre outras disposições. No Brasil, este protocolo foi registrado através do decreto legislativo número 88, de 01 de dezembro de 1992, e decreto número 922, de 10 de setembro de 1993.

\section{CONSIDERAÇÕES FINAIS}

O Mercosul oferece ao Brasil a possibilidade de se tornar o líder de uma região com um PIB de US\$4,7 trilhões; sem conflitos étnicos, de fronteira, religiosos, históricos ou culturais; com sistemas financeiros relativamente desenvolvidos; uma tradição capitalista de décadas; um parque industrial de porte razoável; consumo de massa; e uma considerável demanda reprimida, visto se tratar de uma região com uma renda per capita média, porém com bolsões de pobreza expressivos e portanto com grande potencial de expansão 
de consumo. O Mercosul é o grande expoente brasileiro no cenário internacional, nas relações econômicas e até mesmo políticas, possibilitando uma maior estrutura de negociação. Ao gozar do status de bloco econômico, é visto por muitos como uma forma de fugir da gigantesca influência dos Estados Unidos na América Latina, que é uma constante preocupação, no que diz respeito a manter tradições e costumes culturais singulares dos latinos.

\section{REFERÊNCIAS}

BÊRNI, D. A.. A marcha do Mercosul e a marcha da globalização. In: Reis, C. N.. América Latina: crescimento no comércio mundial e exclusão social. Porto Alegre: Dacasa /Palmarica, 2001.

BULMER-THOMAS, V.. A União Europeia e o Mercosul: perspectivas de um tratado de livre comércio e suas implicações sobre os Estados Unidos. In: Reis, C. N.. América Latina: crescimento no comércio mundial e exclusão social. Porto Alegre: Dacasa/Palmarica, 2001.

KRUGMAN, P.; OBSFELD, M.. Economia internacional: teoria e prática. São Paulo: Makron Books, 2001.

SALAMA, P.. Novos paradoxos da liberação na América Latina? In: Reis, C. N. América Latina: crescimento no comércio mundial e exclusão social. Porto Alegre: Dacasa/Palmarica, 2001.

ALMEIDA, P. R.. Mercosul e ALCA na perspectiva do Brasil: uma avaliação política sobre possíveis estratégias de atuação, 2002.

AVERBUG, M.. Mercosul: Expectativas e Realidade. Revista do BNDES, Rio de Janeiro, v.9, n.17, p.75-98, 2002.

BARBIERO, A.; CHALOULT, Y. O Mercosul e a nova ordem econômica internacional. Revista Brasileira de Política Internacional, Brasília, v.44, n.1, p.23-41, 2001.

BAUMMANN, R.; CARNEIRO, F. G.. Os agentes econômicos em processo de integração regional - inferências para avaliar os efeitos da ALCA. Brasília: Universidade de Brasília, 2002.

BRAGA, M. B.. Integração econômica regional na América Latina: uma interpretação das contribuições da CEPAL. Revista Cadernos PROLAM/USP: São Paulo, v.1, n.1, 2002.

CAVALCANTI, M. A. F. H.. Integração econômica e localização sob concorrência imperfeita. Rio de Janeiro1997.

CARVALHO, A.; PARENTE, A.. Impactos comerciais da área de livre comércio das Américas. Rio de Janeiro: IPEA, 1999.

COZENDLEY, C. M.; BENJAMIM, D. A.. Laudos Arbitrais no marco do Protocolo de Brasília: a construção jurídica do processo de integração. In: Solução de Controvérsias no Mercosul. Brasília: DOU, 2003.

GARCIA, A. A.. O impacto da ALCA na economia brasileira: alguns comentários. Indicadores Econômicos FEE: Porto Alegre, v.29, n.3, 2001.
GIAMBIAGI, F.; MARKWALD, R.. A estratégia de inserção do Brasil na economia mundial: Mercosul ou lonely runner?. Rio de Janeiro: Ensaios BNDES, 2002.

GIAMBIAGI, F.; MOREIRA, M. M.. Políticas neoliberais? Mas o que é o Neoliberalismo?. Revista do BNDES, Rio de Janeiro, v.7, n.13, p.171-190, 2000.

KUME, H.; PIANE, G.. Mercosul: dilema entre união aduaneira e área de livre-comércio. Rio de Janeiro: IPEA, 2001.

MACHADO, J. B. M.. Mercosul: processo de integração: origem evolução e crise. São Paulo: Aduaneira, 2000.

MONTOYA, M. A. Os custos e benefícios da integração econômica do grupo andino: uma análise do comércio intraregional do setor agropecuário. Análise Econômica, Rio Grande do Sul, v.12, p. 74-92, 1994.

MOURO, L. C.. A consolidação da Arbitragem no Mercosul: O sistema de solução de controvérsias após 8 laudos arbitrais. In: Solução de Controvérsias no Mercosul. Brasília: DOU, 2003.

ARAÚJO, N.. O papel da tradição do Common Law nos laudos arbitrais do Mercosul: Considerações sobre a utilização dos princípios em seu processo decisório. In: Solução de Controvérsias no Mercosul. Brasília: DOU, 2003.

PRADO, L. C. D.. Mercosul como opção estratégica de integração: notas sobre a teoria da integração e estratégias de desenvolvimento. Ensaios FEE, Porto Alegre, v.18, n.1, p.276-299, 1997.

MARTINS, H.; RIBEIRO, E. S.; SANTORO, M.. Parlamento do Mercosul: forma de organização e perspectivas à participação social e às políticas públicas. Observatório Político SulAmericano, Rio de Janeiro, v.2, n.12, 2007.

PINCHEMEL, F.; RIBEIRO, E. S.. Paradigmas da atuação brasileira no Mercosul. Revista Universitas: Relações Internacionais, Brasília, v.9, n.1, 2011.

RIBEIRO, E. S.. Políticas de Educação no Mercosul. Revista Universitas Humanas, Brasília, v.7, n.1-2, 2010.

REIS, R. N.; RIBEIRO, E. S.. Um Parlamento para o Mercosul: o processo político e histórico de sua criação. Revista Universitas: Relações Internacionais, Brasília, v.5, n.1-2, 2007.

ROSENTHAL, G.. Regionalismo aberto na América Latina e no Caribe: a integração econômica a serviço da transformação 
produtiva com equidade. In: Cinquenta anos de

Pensamento na CEPAL. Santiago do Chile, p.939-958, 1994.

MENDONÇA, M. J. C.; NONNEMBERG, M. H. B.. Criação e desvio de comércio no Mercosul: o caso dos produtos agrícolas. Rio de Janeiro: IPEA, 1999.

SABBATINI, R.. Multilateralismo, regionalismo e o Mercosul. Indicadores Econômicos FEE: Porto Alegre, v.29, n.1, 2001.
SALVATORE, D.. Economia internacional. Rio de Janeiro: LTC, 2000.

VEIGA, P. M.. A infraestrutura e o processo de negociação da ALCA. Rio de Janeiro: IPEA, 1999.

VERA-FLUIXÁ R. X.. Principios de integración regional en América Latina y su análisis compartivo con la Unión Europea. Bonn, 2000. 